\title{
MTHFR rs1801133 polymorphism in Bangladeshi population - its prevalence and detection
}

\author{
Sumaiya Farah Khan ${ }^{a^{*}}$, Mahmuda Akter ${ }^{\mathrm{a}}$, Shayan Shahriar ${ }^{\mathrm{b}}$, MD Amzad Hossain ${ }^{\mathrm{a}}$, Abu Ashfaqur Sajib ${ }^{\mathrm{b}}$ \\ ${ }^{a}$ Department of Genetic Engineering and Biotechnology, Jagannath University, Dhaka-1100, Bangladesh \\ ${ }^{b}$ Department of Genetic Engineering and Biotechnology, University of Dhaka, Dhaka-1000, Bangladesh
}

Received 19th May 2020 / Accepted 20th October 2020

\begin{abstract}
Methylenetetrahydrofolate reductase (MTHFR) has been reported as a key enzyme not only for intracellular folate homeostasis but also for metabolism. A particular variant (G677A) leads to an altered amino acid, which ultimately causes decreased enzyme activity and may modulate the risk of causing several chronic diseases. The purpose of this study was to detect the pervasiveness of this variant MTHFR rs1801133 G677A in the Bangladeshi population. We applied allele-specific polymerase chain reaction (AS-PCR) to determine the genotypes at the rs1801133 in the Bangladeshi population. We performed targeted sequencing of the AS-PCR product of randomly selected samples. Out of the 181 Bangladeshi individuals, $71.8 \%$ had homozygous $677 \mathrm{GG}$ genotype, while $28.2 \%$ comprised of heterozygous $677 \mathrm{GA}$ genotype. No individual with the homozygous 677AA genotype was found in this representative Bangladeshi population. The $677 \mathrm{G}$ alleles had higher frequency (0.856) compared to $677 \mathrm{~A}$ alleles $(0.144)$ at the rs1801133 locus. Though the more risky homozygous 677AA genotype at the rs 1801133 locus is absent in the Bangladeshi population, further association studies can be performed to identify the role of MTHFR mutation in the susceptibility to different multifactorial diseases.
\end{abstract}

Keywords: Allele specific PCR, MTHFR, polymorphism, rs1801133

\section{INTRODUCTION}

Hyperhomocysteinemia, a type of genetic disorder, is manifested by elevated concentrations of homocysteine in plasma and act as a mediator in the development of several medical conditions such as cardiovascular and neurodegenerative diseases, renal dysfunction, diabetes, pregnancyrelated complications, congenital defects, male infertility, osteoporosis, neuropsychiatric disorders and cancer (Yafei et al., 2012). Homocysteine is formed when the amino acid methionine is naturally broken down (i.e., metabolized) to be excreted in the urine (Varga et al., 2005) The produced homocysteine can be recycled within our body with the help of vitamins
B12, B6, folate and an enzyme methylenetetrahydrofolate reductase (MTHFR). Any abnormality of this element hampers the recycling process and therefore causes accumulation of homocysteine in the blood (Moll \& Varga, 2015). Both of environmental and genetic factors influence the plasma levels of homocysteine. However, Dajani et al. (2013) has reported the MTHFR rs1801133 G677A mutation as a potential risk factor.

MTHFR is an enzyme-linked to folate pathway that transforms 5, 10methylenetetrahydrofolate $(5,10-\mathrm{MTHF})$ to 5methyltetrahydrofolate (5-MTHF). As a result,

\footnotetext{
*Author for correspondence: Dr. Sumaiya Farah Khan, Department of Genetic Engineering and Biotechnology, 9, 10 Chittaranjan Avenue, Jagannath University, Dhaka-1100, Bangladesh. Email sumaiyafarah@yahoo.com
} 
homocysteine is re-methylated to methionine. Conversely, methionine can be reversibly hydrolyzed into adenosine and homocysteine and catalyzes the synthesis of purine, DNA and RNA (Lima et al., 2014). Since MTHFR affects several biochemical pathways, including distribution of folate, multiple enzymatic homocysteine metabolism and methylation reactions, a mutation in MTHFR can modify the risk of disease both in a positive and negative fashion (Esfahani et al., 2003). Although a good number of polymorphisms have been identified in the MTHFR gene, the most common rs1801133 G677A missense mutation has been confirmed to decrease $65 \%$ of the enzymatic activity (Rozen, 1997). MTHFR rs1801133 G677A is a nonsynonymous polymorphism at the rs1801133locus, located on chromosome 1p36.3, that substitutes valine for alanine at codon 222 of the MTHFR enzyme that leads to a mild-tomoderate hyperhomocysteinemia (BrezovskaKavrakova et al., 2013).

In current development, pharmacogenetics has also emerged as a novel tool for the individualization of treatment. Thus, various genetic polymorphisms and haplotypes in the MTHFR gene have been analyzed and applied as markers for optimizing treatment outcome that involved in drug transport, metabolism as well as the mechanism of action (De Mattia \& Toffoli, 2009). Several published case-control investigations have demonstrated the probable influence of MTHFR rs1801133 G677A (MTHFR G677A) genetic variants on the efficacy and toxicity of several fluoropyrimidines and antifolate agents (Toffoli \& De Mattia, 2008) such as methotrexate, raltitrexed and 5-fluorouracil that are used in the treatment of rheumatoid arthritis, bowel cancer and colon cancer respectively. In Bangladesh, almost $6.5 \%$ of males and $2.7 \%$ of females suffer from colorectal cancer (Hussain, \& Sullivan, 2013) and the rate of rheumatoid arthritis prevalence was $0.7 \%$ per year in rural populations compared to $0.4 \%$ in urban communities where females were affected six times more than males (Rudan et al., 2015).

The variations in the frequency of the polymorphisms were observed in different geographical gradient and ethnic groups. The pervasiveness of the MTHFR G677A polymorphism has already been studied in
Caucasian, Hispanic and Latino/MexicoAmerican populations as well as in many Asian countries like India, Pakistan, Sri Lanka, Japan and different ethnic groups of China (Yang et al., 2013). In several studies, the homozygous variant allele MTHFR 677AA was found to be associated with severely impaired phenotype, with a frequency often reported to be high in Europe (0.241- 0.643), and low in Africa (0-0.355) (Yang et al., 2013). However, the homozygous 677GG and the heterozygote $677 \mathrm{GA}$ are quite common among various populations. In contrast, until recently no research was conducted on the frequency of MTHFR rs1801133 polymorphism in the Bangladeshi community. Realizing the need for the analysis of this variant, the study was designed to investigate the pervasiveness of MTHFR rs1801133 polymorphism in general and healthy Bangladeshi population.

\section{MATERIALS AND METHODS}

\section{Blood sample collection and DNA isolation}

A total of 181 blood samples were collected from random Bangladeshi individuals (105 females and 76 males) living in the Dhaka city. Subjects were unrelated, apparently healthy, with average age of 38.16 and 40.55 years for females and males, respectively. This study was approved by the ethics review committee of the Faculty of Biological Sciences, University of Dhaka. Blood samples were collected in $\mathrm{K}_{2}$-EDTA coated collection tubes and DNA was extracted from the collected samples using the PureLink ${ }^{\mathrm{TM}}$ Genomic DNA Mini Kit (K1820-01, Thermo Fisher Scientific Corp.) following the manufacturer's protocol.

\section{Allele-specific PCR}

Allele-specific primers were designed for the rs1801133 SNP locus based on the principle described by Wangkumhang et al., 2007 (Table 1). Primer-BLAST tool was used to check the specificities of the designed primers (Ye et al., 2012). Temperature-gradient PCR was executed in a PCR machine to optimize the annealing condition for the primer pairs in PCR.

A sufficient amount (10-50 ng) of genomic DNA template was used for PCR reaction with 
$2.5 \mu \mathrm{L}$ of $10 \times$ DreamTaq Green Buffer, $0.75 \mu \mathrm{L}$ of $10 \mathrm{mM}$ dNTP mix (18427088; Invitrogen ${ }^{\mathrm{TM}}$ ), $0.5 \mu \mathrm{L}$ of common forward primer $(10 \mu \mathrm{M}), 0.5$ $\mu \mathrm{L}$ of allele-specific reverse primer $(10 \mu \mathrm{M}), 0.2$ $\mu \mathrm{L}$ of DreamTaq Green DNA Polymerase (EP0712, Thermo Fisher Scientific), and PCR grade water. The final volume was $25 \mu \mathrm{L}$. All the primers were obtained from Macrogen Inc (South Korea). An equal volume of PCR grade water was added as a negative control PCR in lieu of genomic DNA. A total of 34 cycles reaction condition was: an initial denaturation step at $95^{\circ} \mathrm{C}$ for $2 \mathrm{~min}$, denaturation at $94^{\circ} \mathrm{C}$ for $30 \mathrm{sec}$, annealing at an appropriate temperature (Table 1) for $1 \mathrm{~min}$, and elongation at $72^{\circ} \mathrm{C}$ for $20 \mathrm{sec}$, followed by a final hold at $4^{\circ} \mathrm{C}$. An equal volume of the wild and variant allele-specific PCR products were mixed with loading buffer and resolved in 1.5\% agarose gel electrophoresis with $0.5 \times$ Tris-acetate-EDTA (TAE) buffer along with DNA markers. The agarose gel containing the separated PCR products was then stained with ethidium bromide in TAE buffer. Then, they were observed and photographed in a gel documentation system. The banding pattern image of gel photographs determined the genotype of MTHFR rs1801133 locus.

\section{DNA sequencing}

To assess the specificity of AS-PCR, a different primer (for sequencing) in combination with the common forward primer (Table 1) for the MTHFR rs1801133 locus was used to amplify the corresponding SNP encompassing region. A sufficient amount (10-50 ng) of genomic DNA template was used for PCR reaction. The final volume was $25 \mu \mathrm{L}$ containing $2.5 \mu \mathrm{L}$ of $10 \times$ DreamTaq Green Buffer $0.75 \mu \mathrm{L}$ of $10 \mathrm{mM}$ dNTP mix $0.5 \mu \mathrm{L}$ of each primer $(10 \mu \mathrm{M}), 0.2 \mu \mathrm{L}$ of DreamTaq Green DNA Polymerase and PCR grade water. The thermal cycler profile was as follows: initial denaturation at $95^{\circ} \mathrm{C}$ for $2 \mathrm{~min}, 34$ cycles each with denaturation at $94^{\circ} \mathrm{C}$ for $30 \mathrm{sec}$, annealing at $58.5^{\circ} \mathrm{C}$ for $1 \mathrm{~min}$, and elongation at $72^{\circ} \mathrm{C}$ for $30 \mathrm{sec}$ followed by a single elongation step at $72^{\circ} \mathrm{C}$ for $5 \mathrm{~min}$ and a final hold at $4^{\circ} \mathrm{C}$. $1.0 \%$ agarose gel was used to resolve the PCR amplified sequences with $0.5 \times$ TAE buffer and DNA ladder (300003; GeneON). After staining with ethidium bromide in TAE buffer, the products were visualized in a gel documentation system. According to the manufacturer's protocol, FavorPrep ${ }^{\text {TM }}$ GEL/PCR Purification Kit was used to purify the PCR products. The quality and quantity of the purified PCR products were analyzed in a NanoDrop ${ }^{\text {TM }} 2000$ spectrophotometer. These purified PCR products were sent to Macrogen Inc. (South Korea) for sequencing. SnapGene Viewer was used to analyze the sequences.

\section{Data Analysis}

Microsoft Excel and GraphPad Prism ${ }^{\circledR}$ software were used to calculate and represent the allele frequencies and genotypes at MTHFR rs1801133 locus in the Bangladeshi population. The $\chi^{2}$ analysis was performed to test the HardyWeinberg equilibrium.

Table 1. Primers used in this study.

\begin{tabular}{|c|c|c|c|c|}
\hline $\begin{array}{c}\text { PCR } \\
\text { product }\end{array}$ & Primer & Sequence, $5^{\prime} \rightarrow 3^{\prime}$ & $\mathbf{T}_{\mathrm{m}}\left({ }^{\circ} \mathbf{C}\right)$ & $\begin{array}{l}\text { Product } \\
\text { size (bp) }\end{array}$ \\
\hline \multirow{2}{*}{ Wild type } & rs1801133_Common Forward & ACTGTCATCCСTATTGGCAG & \multirow{2}{*}{60.5} & \multirow{2}{*}{172} \\
\hline & rs1801133_W_Reverse & CTGCGTGATGATGAAATCCG & & \\
\hline \multirow{2}{*}{$\begin{array}{l}\text { Variant } \\
\text { type }\end{array}$} & rs1801133_Common Forward & ACTGTCATCCCTATTGGCAG & \multirow{2}{*}{58.5} & \multirow{2}{*}{118} \\
\hline & rs1801133_M_Reverse & CTGCGTGATGATGAAATCCA & & \\
\hline \multirow{2}{*}{ Sequencing } & Forward & ACTGTCATCCCTATTGGCAG & \multirow{2}{*}{58.5} & \multirow{2}{*}{252} \\
\hline & Reverse & GGGTGGAGGGAGCTTATG & & \\
\hline
\end{tabular}




\section{RESULTS}

In the current study, allele-specific polymerase chain reaction method was applied to determine allele frequencies and corresponding genotypes at the clinically significant rs1801133 locus (Figure 1). The confirmation of allele-specific genotypic data was achieved by targeted sequencing of DNA collected from randomly selected samples (Figure 2).

A total of 181 samples were collected randomly to perform this study. In this representative Bangladeshi population, the frequency of $677 \mathrm{G}$ and $677 \mathrm{~A}$ alleles at the rs1801133 locus of MTHFR gene were found to be 0.856 and 0.144 , respectively (Figure $3 \mathrm{~A}$ ). Among 181 subjects, 130 individuals were found with homozygous 677GG genotype, which covers $71.8 \%$ of the studied population (Figure $3 \mathrm{~B})$. Only $28.2 \%$ of the studied population comprised of heterozygous 677GA genotype, while there was no individual with the homozygous 677AA genotype. This result was significantly similar to the MTHFR rs1801133 genotype data of 86 Bangladeshi individuals collected from the 1000 Genomes Browser (Auton et al., 2015) where $75.6 \%$ individuals were found to be homozygous 677GG genotype and $24.4 \%$ of the 86 studied individuals were heterozygous $677 \mathrm{GA}$ genotype, while there was no individual with the homozygous 677AA genotype.

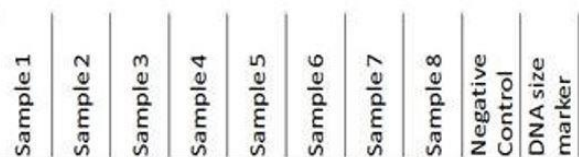

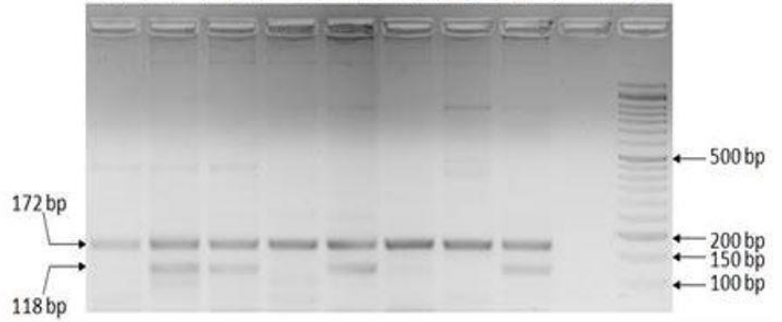

Figure 1. AS-PCR of MTHFR rs1801133 variants. Sizes of the wild type $677 \mathrm{G}$ and variant 677A amplicons are 172 and 118 bps, respectively. In this representative figure, four individuals $(1,4$, 6 and 7) have homozygous 677GG genotype and four individuals harbor heterozygous 677GA genotype (2, 3, 5 and 8$)$.

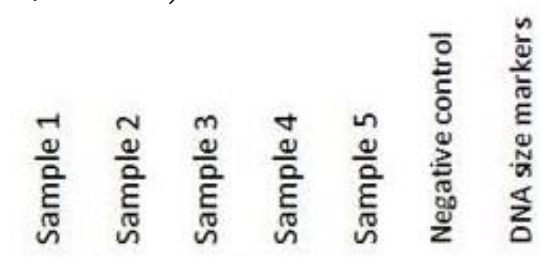

Sample 1
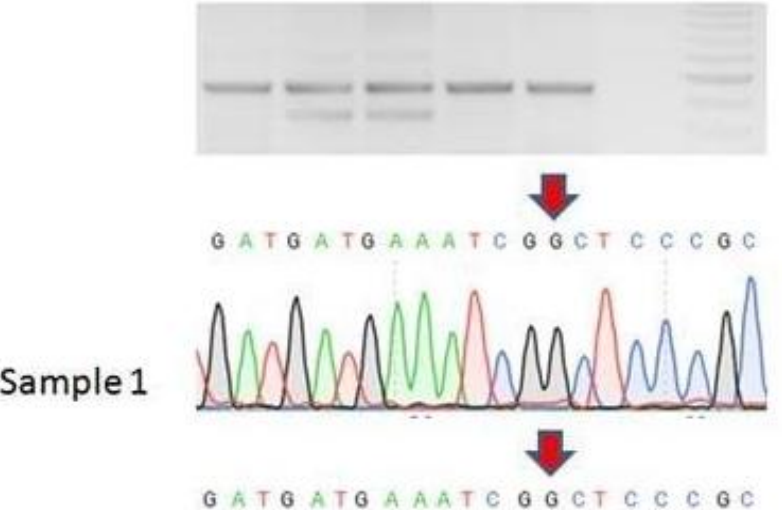

Sample 2

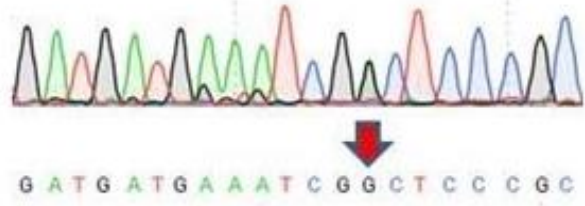

Sample 3

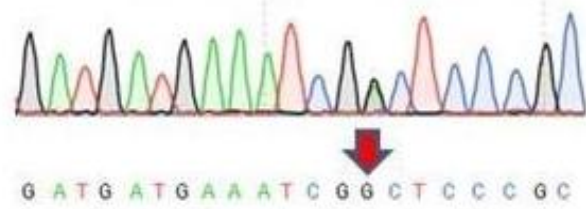

Sample 4

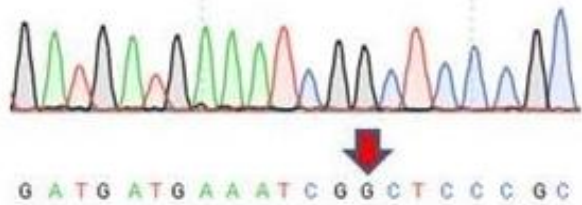

Sample 5

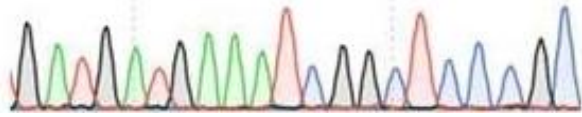

Figure 2. DNA sequence chromatograms of representative samples. A different pair of primers (Table 1) were used in PCR to amplify the region encompassing the MTHFR rs1801133 site for the sequencing purpose. In this representative figure, three individuals (1,4 and 5) have homozygous 677GG genotype and two individuals carry heterozygous $677 \mathrm{GA}$ genotype (2 and 3).

Interestingly, data from both studies combined together with a total of 267 individuals, also showed a similar percentage pattern of genotype where $677 \mathrm{G}$ and $677 \mathrm{~A}$ allele frequencies were 
0.861 and 0.139 , respectively (Figure 3A). The data of the combined population demonstrated that $73 \%, 27 \%$ and $0 \%$ of the individuals had homozygous 677GG, heterozygous 677GA and homozygous 677AA genotypes, respectively, which actually indicate the nearly concordant

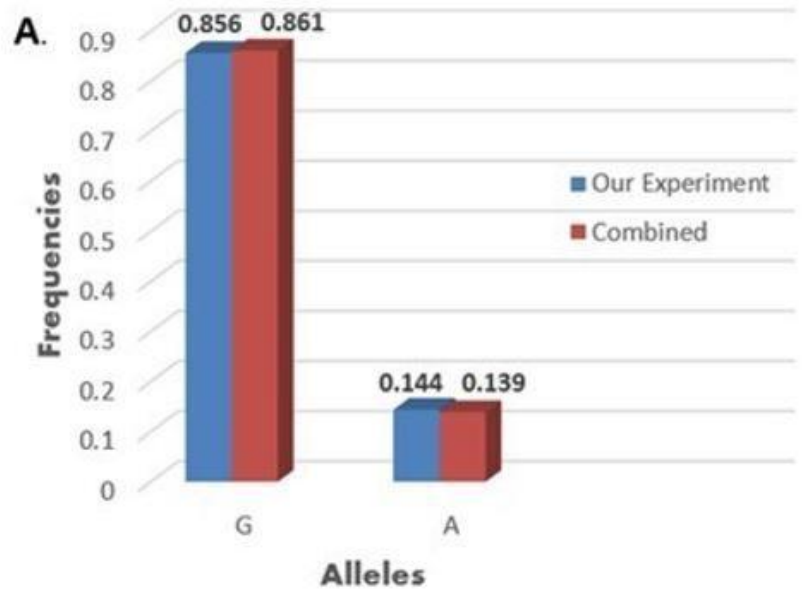

result of the present study (Figure 3B). The genotype frequencies of this polymorphism were in compliance with the Hardy-Weinberg equilibrium $(p<0.05, d f=2)$, reflecting that no selective mechanism for a specific genotype of the polymorphism existed.

Figure 3. Genetic architecture of the Bangladeshi population at the MTHFR rs1801133 locus. A. Frequencies of $677 \mathrm{G}$ and $677 \mathrm{~A}$ alleles in our experiment and combined data with the 1000 Genomes Browser. B. Percentages of different genotypes at the MTHFR rs1801133 locus.

\section{DISCUSSION}

The present study examined the pervasiveness of the G677A variant in the MTHFR gene among randomly selected healthy subjects. Many epidemiological studies have indicated that MTHFR G677A is variable which depends on the location and ethnicity. A study on various ethnic groups in the United States of America reported a higher frequency of a minor allele in the Hispanic population while a lower frequency in the African Americans ( $\mathrm{Li}$ et al., 2005). The variation was also observed among Europeans ranging from 0.20 to 0.55 while the frequency was comparatively lower (0.04 to 0.38) in Asian populations (Rai et al., 2012). The 677A allele frequency (0.144) in our target population actually supports the data, which was reported in other studies on Asian populations.

The genotype variation was also found even in different regions in a similar geographic location (Romero-Sánchez et al., 2015). The world population shows a greater variation of 677AA

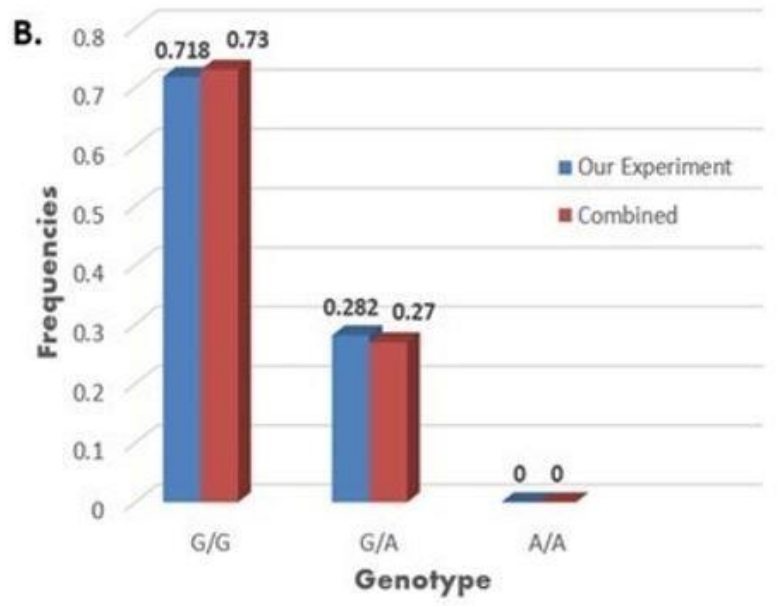

homozygosity, ranging from $0 \%$ to over 30\% (Gonzàlez-Galofre et al., 2010). Among the European populations, the highest prevalence of the mutant homozygous allele was observed in the Italian while the lowest persistence was found in the German population. Outside Europe, the variation in the prevalence of the homozygous polymorphism was 10 to $14 \%$ in America, Australia, Canada and Brazil (Liew \& Gupta, 2015). The frequencies of MTHFR rs1801133 genotypes in countries of different continents are shown in Figure 4. The frequencies of homozygous 677AA genotype vary from $0 \%$ to $30 \%$ in the world populations (Romero-Sánchez et al., 2015). From the 1000 Genome Browser study, it was found that two South Asian countries (SAS) such as Punjabi from Lahore in Pakistan (PJL) and Sri Lankan Tamil from the UK (STU) had no homozygous 677AA genotype in their population like Bangladeshi population (BEB). The homozygous 677AA genotype was also absent in some African populations, while the rest of the countries of different continents show a range of distributions (Figure 4). 


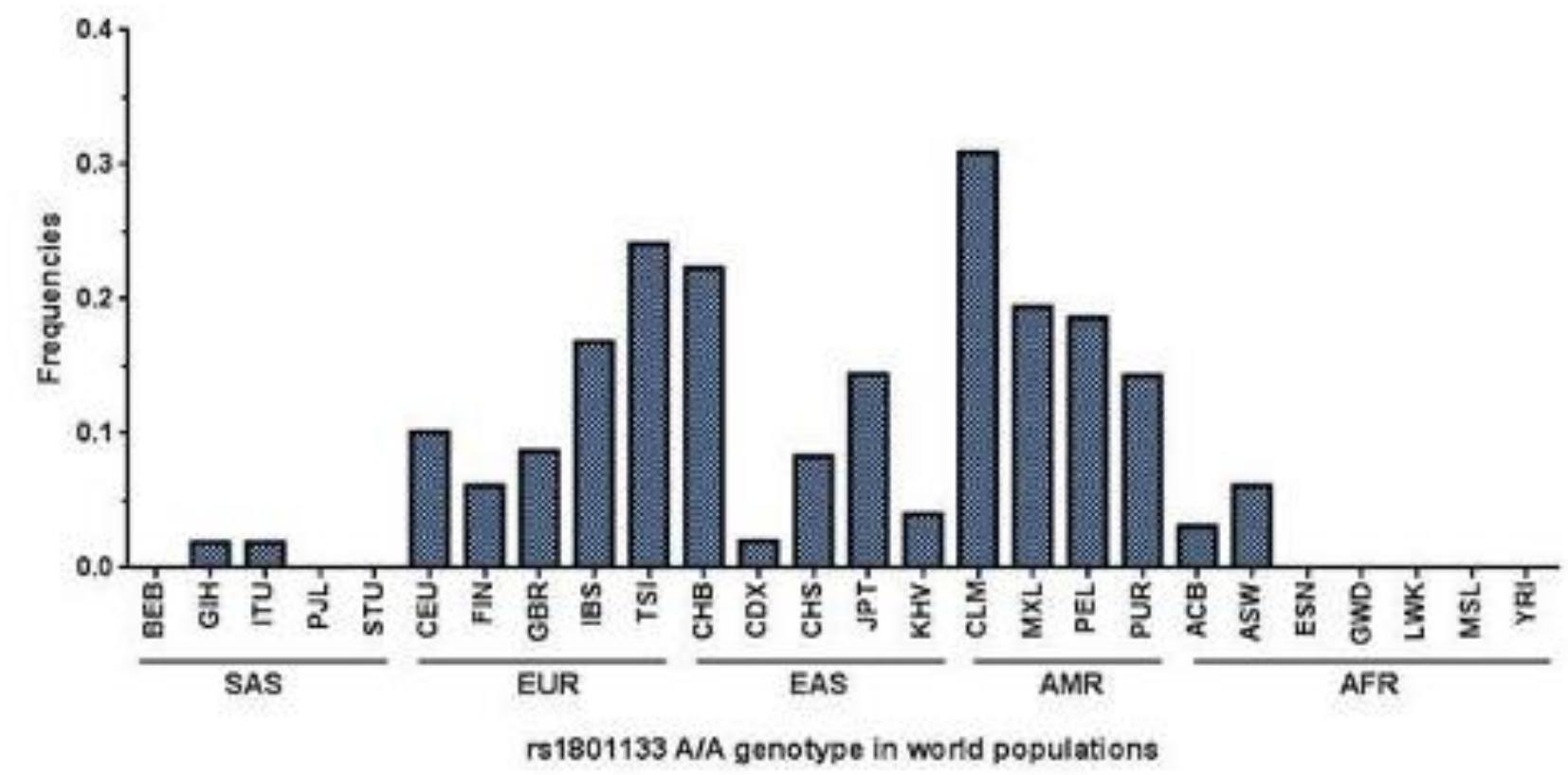

Figure 4. The frequency of MTHFR rs1801133 homozygous 677AA genotype in world populations. Here, $\mathrm{SAS}=$ South Asian, EUR=European, EAS=East Asian, AMR=Admixed American, AFR=African.

In our present study, the wild type homozygous 677GG genotype (0.718) was most frequently observed, followed by heterozygous 677GA (0.282). The study did not find any homozygous 677AA genotype in the target population. The percentage of the homozygous mutant $677 \mathrm{AA}$ was reported approximately $0 \%, 1.9 \%, 6 \%$ and $3.9 \%$ in Tamil (Angeline et al., 2004), Pakistani (Iqbal et al., 2016), North Indian (Kohli et al., 2007) and Lebanese (Sabbagh et al., 2008) healthy population respectively. Considering the different ethnic groups, the Chinese Han population showed $23.2 \%$ overall frequencies of the homozygous 677AA genotype (Yang et al., 2013).

Till now, the reasons behind these geographical and ethnic differences are not clear and there may be an involvement of genetic and environmental factors. The regional variation among populations may be indicative of selective advantages and disadvantages under particular conditions (Fodil-Cornu et al., 2009). Several reports also suggest that in different parts of the world, environmental selective pressures condition the $677 \mathrm{G}$ and $677 \mathrm{~A}$ allele frequencies (Fodil-Cornu et al., 2009). It can be found from several investigations that UV radiation (Cordain \& Hickey, 2006), evolution and migration (Underhill et al., 2000), living environment (Botto \& Yang, 2000) food habit especially folate intake
(Wang et al., 2011), genetic drift (Rosenberg et al., 2002), gene-gene (Diamond, 2005) and geneenvironment interactions (Ke et al., 2001) could be the reasons for various geographical gradient. Furthermore, accurate genotype patterns of this MTHFR rs1801133 locus may be helpful for further gene-disease correlations study, population genetics and health effect evaluation.

The reports of several case-control studies that focused on the association of genotype with diseases are complicated and not constant. The existence of MTHFR G677A mutation (heterozygous 677GA or homozygous 677AA form) may influence the incidence of acute myocardial infarction in the Tamil population and especially the Caucasians who are young/middleaged ( $<50$ years). In the same case, associations were not found in elderly male or female Caucasians, people of East Asia and South Asia and African-Americans (Xuan et al., 2011). In the Chinese population, homozygous MTHFR 677AA and heterozygous MTHFR 677GA genotypes play a significant role in developing esophageal cancer. But the inverse relationship was found in Japanese and German people (Zhao et al., 2011). The antagonistic association results obtained across independent studies may be partly explained by the distributional variation in genotype. This phenomenon reminds us that 
association studies of MTHFR rs1801133 mutations with several diseases should warrant more attention in this region.

Here, a simple yet efficient AS-PCR-based method was reported to clarify the genotype of individuals at the MTHFR rs1801133 locus. The data of allele-specific genotype exhibited accordant results in their analogous DNA sequence chromatograms (Figure 2). The ASPCR-based method is easy but precise. These are the prominent advantages of this method over the restriction enzyme-based or hybridization methods (Islam et al., 2018). This simple, quick and cost-effective technique can be conducted in a fundamental laboratory setting and requires only a few hours to determine the MTHFR rs1801133 genotype.

Although the results of our study have potential importance, we are also concerned about the possible limitations of the sample size used and the gender effect. Tribal populations of our country should be considered in order to determine the real existence of the MTHFR rs1801133 genotype pattern.

\section{CONCLUSION}

Our findings represent the pervasiveness of the MTHFR rs1801133 polymorphism and the pattern of genotype in our community. This baseline data can be further helpful to design casecontrol studies and to explore whether there is any impact of genotype on several diseases. From public health standpoint, the data can be useful to help both government and health care professionals to generate the idea of preventive measures as well as to recommend an appropriate drug, dose and dietary habit on the basis of the patient's genotype.

\section{ACKNOWLEDGEMENTS}

The authors express gratitude to the UGC and research cell of Jagannath University for their brace.

\section{REFERENCES}

Angeline, T., Jeyaraj, N., Granito, S., \& Tsongalis, G. J. 2004. Prevalence of MTHFR gene polymorphisms (C677T and A1298C) among Tamilians. Experimental and Molecular Pathology 77(2): 85-88.

Auton, A., Brooks, L. D., Durbin, R. M., Garrison, E. P., \& Kang H. M., et al. 2015. 1000 Genomes Project Consortium, A global reference for human genetic variation. Nature 6: 6874.

Botto, L. D. \& Yang, Q. 2000. 5, 10-Methylenetetrahydrofolate reductase gene variants and congenital anomalies: a HuGE review. American Journal of Epidemiology 151(9): 862-877.

Brezovska-Kavrakova, J., Krstevska, M., Bosilkova, G., Alabakovska, S., Panov, S., \& Orovchanec, N. 2013. Hyperhomocysteinemia and of methylenetetrahydrofolate reductase (C677T) genetic polymorphism in patients with deep vein thrombosis. Materia Socio Medica 25(3): 170-174.

Cordain, L. \& Hickey, M. S. 2006. Ultraviolet radiation represents an evolutionary selective pressure for the south-to-north gradient of the MTHFR 677TT genotype. The American Journal of Clinical Nutrition 84(5): 1244-1245.

Dajani, R., Fathallah, R., Arafat, A., Abdul Qader, M. E., Hakooz, N., Al-Motassem, Y., \& El-Khateeb, M. 2013. Prevalence of MTHFR C677T single nucleotide polymorphism in genetically isolated populations in Jordan. Biochemical Genetics 51: 780-788.

De Mattia, E. \& Toffoli, G. 2009. C677T and A1298C MTHFR polymorphisms, a challenge for antifolate and fluoropyrimidine-based therapy personalisation. European Journal of Cancer 45(8): 1333-1351.

Diamond, J. 2005. Evolutionary biology: geography and skin colour. Nature 435: 283-284.

Esfahani, S. T., Cogger, E. A., \& Caudill, M. A. 2003. Heterogeneity in the prevalence of methylenetetrahydrofolate reductase gene polymorphisms in women of different ethnic groups. Journal of the American Dietetic Association 103(2): 200-207.

Fodil-Cornu, N., Kozij, N., Wu, Q. \& Rozen, R., \& Vidal, S. M. 2009. Methylenetetrahydrofolate reductase (MTHFR) deficiency enhances resistance against cytomegalovirus infection. Genes Immunology. 10: 662-666.

González-Galofre, Z. N., Villegas, V., \& Martínez-Agüero, M. 2010. Preliminary population study of Methylenetetrahydrofolate Reductase (MTHFR) C677T polymorphism determination in a pilot group of students from the University of Rosario. Revista Ciencias de la Salud 8(1): 7-21.

Hussain, S. A. \& Sullivan, R. 2013. Cancer Control in Bangladesh. Japanese Journal of Clinical Oncology 43(12): 1159-1169.

Iqbal, M. P., Iqbal, K., Tareen, A. K., Parveen, S., Mehboobali, N., Haider, G., \& Iqbal, S. P. 2016. Polymorphisms in MTHFR, MS and CBS genes and premature acute myocardial infarction in a Pakistani population. Pakistan Journal of Pharmaceutical Sciences 29(6): 1901-1906.

Islam, T., Rahman, M. S., Paul, N., Akhteruzzaman, S., \& Sajib, A. A. 2018. Allele specific detection of SLC22A2 rs316019 variants associated with metformin disposition through kidney. International Journal of Diabetes Metabolism 24(1-4): 2228.

Ke, Y., Su, B., Song, X., Lu, D., Chen, L., Li, H., \& Qi, C. et al. 2001. African origin of modern humans in East Asia: a tale of 12,000 Y chromosomes. Science 292(5519): 1151-1153.

Kohli, U., Arora, S., Kabra, M., Ramakrishnan, L., Gulati, S., \& Pandey, R. 2007. Prevalence of MTHFR C677T polymorphism in north Indian mothers having babies with 
Trisomy 21 Down syndrome. Down Syndrome Research and Practice 12(2): 133-137.

Li, D. H., Ahmed, M., Li, Y. N., Jiao, L., Chou, T. H., \& Wolff, R. A. 2005. 5, 10-Methylenetetrahydrofolate reductase polymorphisms and the risk of pancreatic cancer. Cancer Epidemiology, Biomarkers \& Prevention 14(6): 1470-6.

Liew, S. C. \& Gupta, E. D. 2015. Methylenetetrahydrofolate reductase (MTHFR) C677T polymorphism: epidemiology, metabolism and the associated diseases. European Journal of Medical Genetics 58(1): 1-10.

Lima, A., Monteiro, J., Bernardes, M., Sousa, H., Azevedo, R., Seabra, V., \& Medeiros, R. 2014. Prediction of methotrexate clinical response in Portuguese rheumatoid arthritis patients: implication of MTHFR rs1801133 and ATIC rs4673993 polymorphisms. BioMed Research International 1-11.

Moll, S. \& Varga, E. A. 2015. Homocysteine and MTHFR mutations. Circulation 132 (1): e6-e9.

Rai, V., Yadav, U., \& Kumar, P. 2012. Prevalence of methylenetetrahydrofolate reductase C677T polymorphism in eastern Uttar Pradesh. Indian Journal of Human Genetics 18(1): 43-46.

Romero-Sánchez, C., Gómez-Gutierrez, A., Gómez, P. E., CasasGomez, M. C., \& Briceño, I. 2015. Gene polymorphism frequency of C677T (rs1801133) MTHFR in Colombian population. Colombia Médica 46(2):75-79.

Rosenberg, N., Murata, M., Ikeda, Y., Opare-Sem, O., Zivelin, A., Geffen, E., \& Seligson, U. 2002. The frequent 5, 10 methylenetetrahydrofolate reductase C677T polymorphism is associated with a common haplotype in whites, Japanese, and Africans. American Journal of Human Genetics 70(3): 758762.

Rozen, R. 1997. Genetic predisposition to hyperhomocysteinemia: deficiency of methylenetetrahydrofolate reductase (MTHFR). Thrombosis and Haemostasis 78(1): 523- 526.

Rudan, I., Sidhu, S., Papana, A., Meng, S., Xin-Wei, Y., \& Wang W, et al. 2015. Prevalence of rheumatoid arthritis in lowand middle-income countries: A systematic review and analysis. Journal of Global Health 5(1): 010409.

Sabbagh, A. S., Mahfoud, Z., Taher, A., Zaatari, G., Daher, R, \& Mahfou, R. A. R. 2008. High prevalence of MTHFR gene A1298C polymorphism in Lebanon. Genetic Testing 12(1): $75-80$.

Toffoli, G. \& De Mattia, E. 2008. Pharmacogenetic relevance of MTHFR polymorphisms. Pharmacogenomics 9(9): 1195-1206.

Underhill, P. A., Shen, P., Lin, A. A., Jin, L., Passarino, G., Yang, W. H., \& Kauffman, E. et al. 2000. Y chromosome sequence variation and the history of human populations. Nature Genetics 26: 358-361.

Varga, E. A., Sturm, A. C., Misita, C. P., \& Moll, S. 2005. Homocysteine and MTHFR mutations relation to thrombosis and coronary artery disease. Circulation 111(19): e289-e293.

Wang, D., He, Y., Li, Y., Luan, D., Yang, X., Zhai, F. \& Ma, G. 2011. Dietary patterns and hypertension among Chinese adults: a nationally representative cross-sectional study. BMC Public Health 11: 925.

Wangkumhang, P., Chaichoompu, K., Ngamphiw, C., Ruangri, U., Chanprasert, J., \& Assawamakin, A. et al. 2007. WASP: a Web-based allele specific PCR assay designing tool for detecting SNPs and mutations. BMC Genomics 8: 275.

Xuan, C., Bai, X. Y., Gao, G., Yang, Q., \& He, G. W. 2011. Association between polymorphism of Methylenetetrahydrofolate Reductase (MTHFR) C677T and risk of myocardial infarction: A meta-analysis for 8,140 cases and 10,522 controls. Archives of Medical Research 42(8): 677-685.
Yafei, W., Lijun, P., \& Jinfeng, W. 2012. Is the prevalence of MTHFR C677T polymorphism associated with ultraviolet radiation in Eurasia? Journal of Human Genetics 57: 780-786.

Yang, B., Liu, Y., Li, Y., Fan, S., Zhi, X., Lu, X., Zheng, D. W. Q., Wang, Y., \& Sun, G. 2013. Geographical distribution of MTHFR C677T, A1298C and MTRR A66G gene polymorphisms in China: Findings from 15357 Adults of Han Nationality. Plos One 8(3): e57917.

Ye, J., Coulouris, G., Zaretskaya, I., Cutcutache, I., Rozen, S.. \& Madden, T. L. 2012. Primer-BLAST: a tool to design targetspecific primers for polymerase chain reaction. BMC Bioinformatics 13: 134.

Zhao, P., Lin, F., Li, Z., Lin, B., Lin, J., \& Luo, R. 2011. Folate intake, methylenetetrahydrofolate reductase polymorphisms, and risk of esophageal cancer. Asian Pacific Journal of Cancer Prevention 12: 2019-2023. 